\title{
Investigation on the factors of poor performance of grade 12 learners in mathematics in secondary schools in Mpongwe district, Copperbelt province of Zambia.
}

\author{
Dickon Chaka Milambo ${ }^{a}$, Ngoy Mwanabute ${ }^{b}$ \\ The Copperbelt University, ${ }^{a}$ School of Graduate Studies, ${ }^{b}$ School of Mathematics and Natural Sciences, P.O. Box 21692, Jambo \\ Drive, Riverside, Kitwe, Zambia. \\ ${ }^{*}$ Corresponding Author: Dickson Chaka Milambo; Tel: 0969331990; Email: milambodc@gmail.com
}

DOI: 10.29322/IJSRP.11.12.2021.p12028

http://dx.doi.org/10.29322/IJSRP.11.12.2021.p12028

\begin{abstract}
The objective of this study was to investigate on the factors leading to the poor performance in grade 12 Mathematics of leaners at secondary schools in Mpongwe District and to find ways to improve the performance. The data were collected using questionnaires administered to random samples of 38 Mathematics teachers, and 124 grade 12 learners. The statistical techniques used to analyse the survey data include the chi-square tests of independence and homogeneity, Kendall's W and Cochran's Q tests. All statistical tests were evaluated at the 5\% significance level. All analyses were done using SPSS version 20.

The results from the analysis of the survey data indicate that the answers given to most questions were homogeneous with respect to background variables. Cochran's Q tests applied to questions allowing for multiple answers were all significant suggesting that the answers to these questions were not equally selected by the respondents. In addition, the study identified the factors leading to poor performance, and the actions to improve the performance in grade 12 Mathematics. The results of Kendall's W tests were significant suggesting that there was an agreement among the teachers regarding the ranks of these factors (Kendall's W $=0.156, \mathrm{p}$-value $=0.000$ ) and actions (Kendall's $\mathrm{W}=0.170$, p-value $=0.000)$.
\end{abstract}

Keywords: Performance; Learner; Grade 12 Mathematics; Factors.

\section{INTRODUCTION}

The fundamental role of Mathematics lies in its day-to-day application in social sciences, business, economics, medicine, management studies, and many other disciplines, in Zambia as well as other countries in the world. In most countries, including Zambia, Mathematics is a core subject that every leaner is studying at both primary and secondary education (CDC: 2013). This alone gives evidence that the subject is very much important to the intellectual development of an individual. Further, the idea of exposing learners at an early stage to Mathematics indicates that the subject is very much applied in the society. This is supported by Natch and Satoshi (2006) who stated that studying Mathematics plays a very important role in developing human thinking, being more creative, reasonable, and able to analyze problems and to forecast the future.

The need to have a learner that is capable of applying Mathematical ideas is amplified by the Zambian Government recent decision through the Ministry of General Education (MoGE: 2019)) to introduce Science, Technology, Engineering and Mathematics (STEM) Schools, in which Mathematics is one of the key subjects. Unfortunately, with all the interventions that have been put in place so far, 
the performance of grade 12 learners in Mathematics has been very poor not only in Mpongwe District but the entire nation and beyond. For instance, in 2012, Mathematics recorded the highest failure rate at 51.66\% in the school certificate examination (ECZ: 2012), with some secondary schools recording failure rates higher than $70 \%$. Similarly, in the 2019 school certificate examination, $43 \%$ of learners who entered for examination failed Mathematics completely (Zambia Daily mail: 2020).

The poor performance in Mathematics at the national examination was also being experienced in other countries. For instance, in Tanzania, the national form four examination results in 2004, 2005 and 2006 failures in Mathematics were, 70\%, 77\% and 76\% respectively (URT, 2008). A report by HakiElimu (2013) further identified the general performance of the year 2009 that about $27.5 \%$ of the students scored division zero, in the year 2010 failure increased to $49.6 \%$, in the year 2011 failure was $46.4 \%$ and $60.5 \%$ in the year 2012. Despite the poor performance of learners in Mathematics, its application in different spheres of life remains important. Mpongwe, one of the districts in Zambia, has not been spared when it comes to poor performance in Mathematics. For example, in 2020, many secondary schools in Mpongwe District recorded failure rates in excess of 60\% in grade 12 Mathematics. It is against this background that this article investigates on the factors of poor performance of grade 12 learners in Mathematics in Mpongwe district and discuses actions to improve the performance.

\section{LITERATURE REVIEW}

\section{Global Perspective}

Poor performance in Mathematics and science subjects is a worldwide challenge. The importance of quality education in nation building has also been realized by several nations including developed countries. Several developed nations including United States of America (USA) realized that their role as leaders in the world's economy and their capacity to produce wealth and quality jobs depend directly on the ability of education system to produce students who can compete in Mathematics and science dominated industries of the future. Realizing the importance of Mathematics, the former United States of America (USA) President Barak Obama remarked in his speech that, "leadership tomorrow depends on how we educate students today especially in Mathematics, science, technology, and engineering" (Brown, 2011). Obama was convinced that Mathematics underpins critical thinking and enables individual to solve problem which is pre - requisite in leadership. Thus, improving Mathematics and science education has been the priority of the policy making agenda (Anon, 2005).

When it comes to Mathematics, many school children in the UK are struggling to achieve their potential, according to new research done by Rowan Walker (2018). In addition, the recent report from the Education Policy Institute and UCL's Institute of Education shows that England has challenges when it comes to performance of learners in Mathematics among developed countries. The challenges in Mathematic is felt in almost all sectors as David Landsman, Executive Director, Tata Limited said, "We all know that the UK underperforms in Mathematics compared with some of our most important competitors. Young people are enthusiastic and confident about Mathematics, and there are many excellent teachers".

The situation of low learner performance seems to be the same in most countries, for instance, the failure rates in Portugal are high and deficient learning in Mathematics is common place at both the middle and the secondary school levels in Portugal (GAVE, 2000). Among the 40 countries involved in the 2000 and 2003 Program for International Student Assessment (PISA) studies, Portuguese students were ranked among the lowest in science performance (GAVE, 2001). 


\section{Africa level}

While African countries differ from one another in many features, they are broadly similar in key conditions that help or hinder Mathematical development. The story of Mathematical development in Africa is one of potential unfulfilled. Oguy (2009) argued that, based on the outstanding achievements of some individuals and institutions it is clear that no African country lacks talented potential Mathematicians. But without a stronger educational structure at all levels, few of them are able to reach their potential. Africa has a potential to have a stronger base of good performance.

In the Sub-Saharan Africa (SSA), for instance, there are few systems if not none for identifying children and no system for tracking them once identified. Such systems, were they available, might make a small but concrete contribution to mathematical development of African countries. Lack of effort to popularize Mathematics is also another factor of poor performance. Sohail (2012) asserted that, "in the Francophone countries, Mathematics is not a popular subject”. Indeed, Mathematics clubs and journals are generally absent. In some countries they are just organized but without substantial outcomes.

In Nigeria, despite the fact that the government has clearly confirmed the importance of Mathematics by making it a core and compulsory subject at both junior and senior secondary levels (Federal Republic of Nigeria [FRN], 2004), the invested billions of Naira in the teaching and learning of Mathematics has not yielded any significant improvement due to wasteful and inadequate spending of the required resources. Numerous factors were identified by some researchers for the inconsequential performance by students, some of which included: shortage of qualified Mathematics teachers, poor facilities, equipment and instructional materials for effective teaching (Yemi \& Adeshina, 2013), and large pupil-to-teacher ratios. Another major hindrance to better improvement of government spending, is the continued use of traditional chalk and talk methods which are yet to give way to the multimedia teaching methods presently in use in schools in developing nations. Students' performance in Mathematics at both internal and external examinations has remained considerably poor (Ale, 1989). According to The Sun News (“Outrage trails students' poor performance," 2014), out of 1.6 million students that took the 2014 May/June West Africa Senior School Certificate Examination (WASSCE), only a little more than half a million $(31.28 \%)$ passed with the minimum requirement for admission into tertiary institutions.

\section{SADC region}

In most SADC countries Mathematics is offered as a compulsory subject from primary to secondary school. In the Tanzania education curriculum for instance, in spite of being the core and compulsory subject, student's performance in Mathematics in Tanzania had been low for a number of years in Certificate of Secondary Education Examinations (CSEE) (URT, 2008). According to URT (2008) a large number of students fail to pass Mathematics examinations with required grades as the report indicated that national form four examination results in 2004, 2005 and 2006 failures in Mathematics were, 70\%, 77\% and 76\%, respectively. The report by HakiElimu (2013) indicated that the general performance of the year 2009 was about $27.5 \%$ of the students scoring division zero. In the year 2010 failure increased to $49.6 \%$, while in the year 2011 and 2012 failure was $46.4 \%$ and $60.5 \%$, respectively.

Despite the fact that South Africa spends a large budgetary commitment (about $20 \%$ of its annual budget on education) on programmes and initiatives, the entire schooling system is characterized with series of low matriculation pass rates especially in gateway subjects (Mathematics, science and accounting) (Naidoo, 2004). The scenario in terms of learner poor performance in Mathematics is of great worry like in other countries. 
In Namibia, the situation seems to be of no difference, there is an outcry among the key stakeholders about the current performance of learners in Mathematics. The performance of learners in Mathematics and science has raised a strong sense of concern both locally and internationally. Though the low performance is also seen in other subjects, Mathematics and science are the most affected in terms of poor performance. According to a study conducted by the Southern and Eastern Africa Consortium for Monitoring Education Quality (SACMEQ II, 2004), Namibia was ranked below other Southern and Eastern African countries in terms of competencies in Mathematics. The report further showed that Namibian learners scored the least. The Junior School Certificate (JSC) results in Mathematics for 2004 and 2006 show that just a fraction of the learners scored between very well or grade A to average or grade C. While the rest of learners had scores loaded between 'D' and 'U' (un-graded).

\section{Local level}

According to Mbetwa and Kafata (2016) who carried out an investigation into the failure rate in Mathematics and science at grade 12 examinations and its impact to the School of Engineering at the Copperbelt University, researches have been carried out on the improvement of performance in Mathematics in some part of the country. One case in point is the one carried out at Saint Therese Girls Secondary School of Kasama District in Zambia with the aim of improving pupils' academic performance at grade twelve O-level examinations in Mathematics. Among the problems that the school had, was the reduction in academic pass-rate from 100\% to $93.6 \%$ which was noticed in the year 2010 with 2009 grade 12 academic results. In the school mission there was need to maintain high passrate for the school. The study reviewed that, the pass-rate with the use of Mathematics clinics for Mathematics subject contributed to the change of the pass-rate from $93.6 \%$ to $95.7 \%$.

\section{OBJECTIVES}

This study was aimed at investigating on the factors leading to the poor performance in grade 12 Mathematics and exploring on how the performance of Mathematics can be enhanced.

\section{DATA COLLECTION PROCEDURE AND STATISTICAL METHODS USED}

The data for this study were collected using self-administered questionnaires. Simple random samples of 38 out of 57 Mathematics teachers in 13 secondary schools of Mpongwe district, and 124 out of 924 grade 12 learners were selected. The questionnaires were distributed to both Mathematics teachers and grade 12 learners in the samples.

Concerning the statistical techniques. the chi-square test of independence, the chi-square of homogeneity, the Kendall's W test, and the Cochran's Q test were applied to the survey data. The chi-square test of independence was used to check for any association between the background variables and the responses to some questions, and for any association between the responses on the two questions, while the chi-square of homogeneity was conducted to determine whether the responses given by different types of respondents on a given question were homogeneous. In order to check for any agreement among the respondents regarding the responses given to a set of questions, the Kendall's W test was applied to the data. The Cochran's Q test was applied to questions allowing for multiple answers to check if the items, options or answers given were equally selected by the respondents

\section{RESULTS}

\subsection{Chi-square and Cochran's W tests results}

This publication is licensed under Creative Commons Attribution CC BY. 
The chi-square test of homogeneity was applied to some questions of the learners' questionnaire, i.e., question 4 (Q4) about the selfdescription of the performance in Mathematics); Q5 about any difficulties faced by the learners; Q7 (about the teaching standards of Mathematics); Q9 on whether learners are given homework to do at home; Q10 on whether parents assist in doing homework; Q12 on the response of parents towards education; Q13 about the use of ICT in teaching Mathematics; and Q14 about understanding the lessons of Mathematics when ICT tool are used). At the 5\% significance level, the answers given by the learners in most questions (except Question 14) were homogeneous with respect to the three background variables, i.e., gender, age, and school (p-values >0.05), indicating that the opinions and views of the learners on the questions were not diverging much. For Question 14, the answers were diverging with respect to gender $(\mathrm{p}$-value $=0.027)$, age $(\mathrm{p}$-value $=0.000)$, and school $(\mathrm{p}$-value $=0.025)$.

For questions allowing for multiple answers (i.e., Q6 about the difficulties faced by the learners in Mathematics, Q8 about the reasons for poor teaching standards in Mathematics, Q11 about the reasons why parents were not assisting learners to do their homework, and Q5 about the actions to take to improve the performance in Mathematics, all Cochran's Q tests were very significant (all p-values = 0.000 ), indicating that the answers on these questions were not equally selected by the respondents.

For the teachers' survey data, the answers given to Q4 (about the performance of the learners in Mathematics on national examination) were related to gender at the $5 \%$ significance level $\left(\chi^{2}\right.$-value $=8.503, \mathrm{p}$-value $\left.=0.014\right)$ and years of experience $\left(\chi^{2}\right.$-value $=9.801, \mathrm{p}$ value $=0.044$ ), but were not related to qualification ( $p$-value $=0.113$ ). In addition, based on the chi-square tests of homogeneity, the views given by the teachers on the nine factors impacting on the performance of Mathematics (Q6) were homogeneous with respect to the three background variables (all p-values > 0.05). For Q8 (concerning the integration of ICT tools in the delivery of Mathematics lessons), the answers to this question were not related to the background variables (all p-values $>0.05$ ).

Cochran's Q test was significant for both Question 5 (about the comments to justify the answers to Question 4), and Question 6 (Cochran's $\mathrm{Q}=15.053$, $\mathrm{p}$-value $=0.020$ for Question 5, and Cochran's $\mathrm{Q}=18.977$, $\mathrm{p}$-value $=0.015$ ), suggesting that the answers to both questions were not equally selected by the teachers (all p-values $>0.05$ ).

\subsection{Main findings from the pupils' survey}

\section{Difficulties faced by learners in Mathematics}

According to the learners, the difficulties they were facing in Mathematics include the language barrier (13.7\% of the respondents), the lack of understanding the concepts of Mathematics (30.6\%), the difficult nature of the Mathematics subject (7.3\%), the lack of seriousness of the teachers (6.5\%), and the lack of learning materials (6.5\%). The remaining learners (35.5\%) stated that Mathematics was not a difficult subject.

\section{Teaching standards of Mathematics at school}

The teaching standards of Mathematics were considered by most learners (73.4\% of the learners) as good in their respective schools, while the rest of the learners (26.6\%) declared that teaching standards in their schools were poor due to the insufficient number of teachers, the lack of more practice, the inability of the teachers for effective teachings of the Mathematical concepts, and the difficult nature of Mathematics.

\section{Actions to improve the performance of Mathematics}


From the point of view of the learners, the most important actions to take to improve the performance in Mathematics include providing more learning materials for Mathematics (36.3\% of the leaners), recruiting more qualified Mathematics teachers (29\%), and using ICT tools in teaching Mathematics (17.7\%). Other actions mentioned by the learners were the reduction of the class sizes in schools, the introduction of more practice in Mathematics, the sensitisation of the pupils to take away their perception that Mathematics is a difficult subject, and the frequent visits of standard officers to schools to monitor the teachings in Mathematics.

\subsection{Main findings from the teachers' survey}

\section{Integration of ICT tools in the delivery of lessons of Mathematics}

On the question of using ICT tools in teaching Mathematics, most teachers (65.8\% of the total in the sample) were just occasionally integrating ICT tools when delivering Mathematics lessons. When asked to select the factors hindering the use of ICT in teaching Mathematics, teachers selected the factors listed in Table 1.

Table 1: Distribution of frequencies and percentages of factors hindering the use of ICT in teaching Mathematics

\begin{tabular}{cccc}
\hline Number & Factor & Count & $\%$ \\
\hline 1 & Lack of available computers & 14 & 36.8 \\
2 & Insufficient software resources & 19 & 50.0 \\
3 & Lack of appropriate training & 13 & 34.2 \\
4 & Lack of suitable examples of opportunities in using ICT & 12 & 31.6 \\
5 & Lack of competency in using ICT & 9 & 23.7 \\
6 & Lack of experience with ICT & 12 & 31.6 \\
7 & ICT is not a priority & 8 & 21.1 \\
8 & ICT is not relevant & 7 & 18.4 \\
9 & Lack of ideas on how to use ICT & 6 & 15.8 \\
\hline
\end{tabular}

From Table 1, The three most important factors discouraging the use of ICT in Mathematics are the lack of available computers, insufficient software resources, and the lack of appropriate training.

\section{Factors of poor performance in Mathematics and actions to improve the performance}

Sets of statements about the possible factors of poor performance in Mathematics and the possible actions that must be undertaken to improve the performance of Mathematics were given and teachers were requested to rank each factor from 1 (most important) to 13 (least important factor) for factors of poor performance, and from 1 to 12 for actions that must be taken. In order to check if there was an agreement among the teachers regarding the order of importance of the factors for poor performance in Mathematics, and actions to improve the performance, Kendall's test was performed. For both questions, the tests were significant (Kendal's $\mathrm{W}=0.156, \mathrm{p}$-value $=$ 0.000 for factors, and Kendall's $\mathrm{W}=0.170, \mathrm{p}$-value $=0.000$ for actions), suggesting that there was an agreement among the teachers regarding the ranks of the possible factors of poor performance in Mathematics, and the ranks of the possible actions to improve the performance of Mathematics. Tables 2 and 3 display the mean ranks of the factors/actions and their order of importance. Factors/Actions with lower means are the most important.

Table 2: Mean ranks and order of importance of the possible factors of poor performance in Mathematics

\begin{tabular}{ccc}
\hline Factor & Mean \\
Rank & $\begin{array}{c}\text { Order or } \\
\text { importance }\end{array}$ \\
\hline Lack of use of ICT in class & 8.94 & 12 \\
Lack of inspection in schools to monitor teaching and learning & 5.50 & 2 \\
Lack of qualified teachers & 7.56 & 7 \\
Teachers avoiding to teach important topics which are difficult & 5.75 & 4
\end{tabular}

This publication is licensed under Creative Commons Attribution CC BY. 


\begin{tabular}{ccc} 
Language barrier & 8.97 & 13 \\
Large classes & 7.75 & 8 \\
Education level of parents & 8.78 & 11 \\
Inadequate teaching and learning facilities and materials at school & 6.25 & 6 \\
Shortage of teachers & 7.75 & 9 \\
Poor pupils prior background & 6.19 & 5 \\
k of seriousness, preparedness, and commitment on the side of learners & 4.17 & 1 \\
spend on teaching & 7.89 & 10 \\
Perception that Mathematics is a difficult subject & 5.50 & 3 \\
\hline
\end{tabular}

From Table 2, the seven most important factors for poor performance in Mathematics include: Lack of seriousness preparedness, and commitment on the side of learners; Lack of inspection in schools to monitor teaching and learning; Learners' perception that Mathematics is a difficult subject; Teachers avoiding to teach important topics which are difficult; Poor learners' prior background of Mathematics from junior secondary schools; Inadequate teaching and learning facilities and materials at school; Lack of qualified teachers.

Table 3: Possible actions that must be taken to improve the performance of Mathematics

\begin{tabular}{ccc} 
Action & $\begin{array}{c}\text { Mean } \\
\text { Rank }\end{array}$ & $\begin{array}{c}\text { Order of } \\
\text { importance }\end{array}$ \\
\hline Intensify monitoring by standard officers to check on learning and teaching & 7.47 & 8 \\
Provide necessary learning and teaching resources & 4.69 & 1 \\
Reduce the pupil-teacher ratio & 8.39 & 11 \\
Form Mathematics clubs & 5.53 & 5 \\
Teach Mathematics in local language & 7.08 & 7 \\
Employ qualified teachers who can handle all the topics & 5.61 & 6 \\
Integrate ICT tools in lessons & 7.61 & 9 \\
Ensure that learners who qualify to senior secondary have enough pre- & 5.14 & 3 \\
requisite knowledge in Mathematics & & \\
Reduce class sizes & 8.00 & 10 \\
Provide a conducive school environment & 8.56 & 12 \\
Expose learners to past examination questions & 4.75 & 2 \\
Use different teaching methods to enhance learning & 5.17 & 4 \\
\hline
\end{tabular}

The six most important actions to take in order to improve the performance in Mathematics (see Table 3) comprise: Providing necessary learning and teaching resources; Exposing learners to past examination questions; Ensuring that learners who qualify to senior secondary have enough prerequisite knowledge in Mathematics from junior secondary schools; Using different teaching methods that will enhance learning; Forming Mathematics clubs; Employing qualified teachers who can handle all the topics. From the analysis of the learners and teachers survey data, the views and opinions of the learners and the teachers on important and salient issues regarding the performance of Mathematics were not much diverging, implying that both types of respondents had the same understanding of the problems and difficulties related to Mathematics

\section{Conclusion}

The research main objectives were to investigate on the factors leading to the poor performance in grade 12 Mathematics of learners at secondary schools in Mpongwe District and to identify actions to be undertaken in order to improve the performance of grade 12 Mathematics. In order to put these objectives into perspective, the learners' and Mathematics teachers' survey data were analyzed. Arising from the findings of this study, the following recommendations to various authorities and stakeholders were formulated. 
(a) There is need to recruit more qualified Mathematics who will cover all the topics (unlike the prevailing situation where teachers tend to avoid perceived difficult topics). The increase in the number of teachers will also improve the learner-teacher ratio.

(b) Standard officers should intensify monitoring in schools as to ensure effective learning and teaching in various schools.

(c) Learners passing to senior secondary should be well equipped with appropriate pre - requisite to handle senior Mathematics.

(d) School administration should ensure that the Mathematics department has a well-organized Mathematics club. It is through this club that quiz and other academic activities related to Mathematics can be done.

(e) Use of ICT has proved to be a good teaching method that enhances understanding It is hoped that since computer studies is now a compulsory subject at junior secondary, implying that at least each school is equipped with basic ICT tools, Mathematics teachers should take advantage of the availability of these tools and infuse them in their teaching practices.

\section{REFERENCES}

Ale, S. O. (1989) Combating poor achievement in Mathematics ABACUS. The Journal of the Mathematics Association of Nigeria, 19(1), 11-23. Boca Raton

Anon, (2005) Why Research, Open Polytechnic of New Zealand.

Brown, (2011) Modern mathematics and Teacher, London; Cambridge University Press.

Curriculum Development Center (2012) The Zambia Education Curriculum Framework, Lusaka.

Daniel, W. W., (1990) Applied Nonparametric Statistics. Second Edition. PWS-KENT, Boston.

Davis, K. (2003) Change is hard: What science teachers are telling us about reform and teacher learning of innovative practices. Science Education

ECZ (2012) Examinations Council of Zambia; School Certificate and GCE Examiners Reports October/November 2013 Examinations Chief Examiners Report

Federal Republic of Nigeria. (2004). National policy on education (4th Ed.). Lagos: Federal Government Press.

Gave (2000) Fundamental concepts in the Evaluation of scientific Literacy of Portuguese Students, Lisbon, Ministerio de Educacao.

Gave (2001) Results of the International Study PISA 2000. PISA 2000 National Reports. Online November, 2005: http://pisa.oecd.org

HakiElimu, (2013) Joint Civil Society Statement on Government's decision to nullify 2012 Form IV results: HakiElimu.

Mbetwa and Kafata (2016) Investigation into the Failure Rates in Grade Twelve (12) Mathematics and Science and its Impact to the School of Engineering. A Case of Kitwe District of Zambia, international Journal of Scientific \&Technological Research V5(08).

Ministry of General Education (2019) Guide for Implementation of STEM School Education, Directorate of National Science Centre, Lusaka

Naidoo, (2007) Learners Views on Assessments Feedback; Case Study based at a Kwazulu Natal School, Unpublished MEd dissertation, University of Kwazulu natal.

This publication is licensed under Creative Commons Attribution CC BY.

http://dx.doi.org/10.29322/IJSRP.11.12.2021.p12028

www.ijsrp.org 
International Journal of Scientific and Research Publications, Volume 11, Issue 12, December 2021

Natch and Satoshi (2006) Analysis of Mathematics Performance of Grade Five (5) Students in Thailand Using Newman Procedure, Journal of International Cooperation in EducationV9(1), P111-122.

Oguy, (2009) The Attitude and Attitude Change, London, Heinemann

Rowan, (2018) http://research.moash.edu/gh

Sohail, (2012) The Conflict Helix, California, Saga Publications

URT, (2008) A Performance of audit Report on School Inspection Program for Secondary Schools in Tanzania; A Report of the Controller and Auditor General of the republic of Tanzania, Dar es Salaam.

Yemi, T. M. \&Adeshina, A. N. G. (2013) Factors influencing effective learning of Mathematics at senior secondary schools within Gombe Metropolis, Gombe State Nigeria. International Institute for Science, Technology and Education, 4(21), 61-66

Zambia Daily Mail (2020) Implementation of STEM schools in the Zambian Context, V10, Government Printers, Lusaka 